IZA DP No. 4307

The Effect of Power Outages and Cheap Talk on Willingness to Pay to Reduce Outages

Fredrik Carlsson

Peter Martinsson

Alpaslan Akay

July 2009 


\title{
The Effect of Power Outages and Cheap Talk on Willingness to Pay to Reduce Outages
}

\author{
Fredrik Carlsson \\ University of Gothenburg \\ Peter Martinsson \\ University of Gothenburg
}

\author{
Alpaslan Akay \\ IZA and University of Gothenburg
}

Discussion Paper No. 4307

July 2009

IZA

P.O. Box 7240

53072 Bonn

Germany

Phone: +49-228-3894-0

Fax: +49-228-3894-180

E-mail: iza@iza.org

\begin{abstract}
Any opinions expressed here are those of the author(s) and not those of IZA. Research published in this series may include views on policy, but the institute itself takes no institutional policy positions.

The Institute for the Study of Labor (IZA) in Bonn is a local and virtual international research center and a place of communication between science, politics and business. IZA is an independent nonprofit organization supported by Deutsche Post Foundation. The center is associated with the University of Bonn and offers a stimulating research environment through its international network, workshops and conferences, data service, project support, research visits and doctoral program. IZA engages in (i) original and internationally competitive research in all fields of labor economics, (ii) development of policy concepts, and (iii) dissemination of research results and concepts to the interested public.
\end{abstract}

IZA Discussion Papers often represent preliminary work and are circulated to encourage discussion. Citation of such a paper should account for its provisional character. A revised version may be available directly from the author. 
IZA Discussion Paper No. 4307

July 2009

\section{ABSTRACT}

\section{The Effect of Power Outages and Cheap Talk on Willingness to Pay to Reduce Outages*}

Using an open-ended contingent valuation survey, we analyze how (i) experience of a power outage due to one of the worst storms ever to hit Sweden and (ii) a cheap talk script affect respondents' WTP to avoid power outages. Experience significantly increases and a cheap talk script decreases the proportion of respondents with zero WTP. There is no significant effect in either case on stated WTP conditional on a positive WTP. The paper concludes with a discussion on the use of valuation studies shortly after the occurrence of an undesirable event.

JEL Classification: C25, D12, Q41

Keywords: contingent valuation, cheap talk, experience, power outages

Corresponding author:

Alpaslan Akay

IZA

P.O. Box 7240

D-53072 Bonn

Germany

E-mail: akay@iza.org

\footnotetext{
* Financial support from Elforsk is gratefully acknowledged. The paper has benefited from comments by Peter Fritz, Lennart Hjalmarsson, Anders Johansson, Olle Hansson, Per-Olof Nilsson, Håkan Nyberg, Matz Tapper, and two anonymous referees.
} 


\section{Introduction}

Valuation methods, such as contingent valuation and choice experiments, are important economic tools to elicit the value individuals put on non-market goods and services. In many cases, valuation of non-market goods takes place after a major change has occurred, for example after a natural disaster. The objective of the present paper is to study the respective effects of (i) experience of a natural disaster and of (ii) a cheap talk script on stated willingness to pay (WTP). We investigate Swedish households' WTP for avoiding power outages of various durations up to 24 hours by using an open-ended contingent valuation study. First, we study the effect of experience by comparing WTP for avoiding power outages one year before and immediately after the worst storm ever to hit Sweden in terms of its effect on power outages. Experiences from such an event might affect not only people's perceptions about the consequences of power outages, but also their preferences. ${ }^{1}$ In behavioral economics, a number of studies show that people take actions that potentially are contrary to their own interest (see, e.g., Loewenstein, 1996). Furthermore, studies show that people have difficulties forecasting their future utility of a stimuli (Kahneman and Snell, 1992). This has led to an argument that public policy should be guided by so-called experience utility rather than decision utility (see, e.g., Kahneman et al., 1997). Conducting a contingent valuation study on subjects before and after an event is therefore a good opportunity to compare responses of inexperienced and experienced respondents. Second, we study how WTP is affected by the introduction of a cheap talk script to some of the households that received the survey after the storm. In addition to explaining that respondents, for different reasons, may deviate from their true WTP, the script stresses that individuals' responses are sometimes expressions of particular views, in our case that 
everyone should have the right to power without outages (Kahneman et al., 1999). This is explained in greater detail later in the text.

On the evening of 8 January 2005, the storm "Gudrun" hit the southeastern part of Sweden. ${ }^{2}$ Due to the storm, approximately 75 million cubic meters of trees fell. In the worst affected areas, the amount of trees that fell in a few hours was equivalent to the amount normally harvested in five years. Falling trees destroyed approximately 20,000 kilometers of power lines, severely impacting the distribution of power. The storm caused power outages in 663,000 of the approximately 4.5 million households in Sweden (i.e., every seventh household) (Statens Energimyndighet, 2005). Over half of the affected households had their power back within 24 hours, while 68,000 were still without power eight days after the storm and 10,000 households still did not have power after three weeks. In fact, there were some cases where it took over a month before power returned. Power outages do of course occur in Sweden from time to time, but the geographical spread and the lengths of the outages were unique. ${ }^{3}$

We conducted the original contingent valuation study in May 2004, and used an openended contingent valuation survey to elicit individuals’ maximum WTP for avoiding power outages of various durations up to 24 hours. Conducting exactly the same study after the storm (hence using exactly the same design), but on a different random sample of respondents, gives us the opportunity to study the influences of the storm on people's valuations of power outages. ${ }^{4}$ Personal experience could result in an increased WTP for some people, but it could also have the opposite effect for individuals who come to realize 
that they did not suffer from the outages as much as they had expected. WTP may also decrease for people who take preventive action to avoid the negative consequences of future outages by for example buying candles, batteries, and/or alcohol stoves. Overall, it is not clear what effect personal experience of Gudrun has on WTP, if any. Moreover, people generally do have some previous experiences of outages, although on average they have been local and much shorter. The views expressed in the media were to a large extent focused on the inability of the power companies to handle the situation and that customers have the right to have the power back as soon as possible irrespective of the costs to the power companies.

To conduct our study we used an open-ended contingent valuation survey, despite the fact that practitioners generally prefer the closed-ended elicitation format. ${ }^{5}$ Two important reasons for the skepticism toward open-ended questions are that they are more difficult to answer and that the question format is not incentive compatible (Carson et al., 2000). However, the open-ended format also has many advantages: in particular that the exact WTP information is obtained from each respondent, and that there are no potential anchoring effects on the bid. In addition, the general tendency found in the literature is that the open-ended format results in lower WTP estimates than the closed-ended format when used in a hypothetical setting (e.g., Brown et al., 1996; Kriström, 1993). Furthermore, experiments comparing hypothetical and actual WTP have shown that the hypothetical bias is not higher, but actually lower, for the open-ended format compared with the closedended format (e.g., List and Gallet, 2001; Balistreri et al., 2001). However, it may also be the case that not all respondents want to overstate their WTP in a hypothetical survey 
situation. In particular, this has been suggested to be the case in many open-ended studies; a respondent whose expected cost of a scenario is larger than his or her WTP has incentives to state a zero WTP. In many open-ended studies, the fraction of respondents with zero WTP is non-negligible. At the same time, respondents with an expected cost lower than the WTP have incentives to overstate their WTP in an open-ended WTP.

During the month after the storm, newspapers, radio, and TV were full of reports about the effects of the storm - both direct effects among those suffering and indirect effects (for example, it took one month to get the trains operating on a normal schedule again). Then, when most of the damages had been repaired, the media started to focus on the responsibility the power companies have to provide their consumers with power. The other main issue discussed in the media was clearing the forest of fallen trees. ${ }^{6}$ One reason why the storm had such a devastating effect on the power provision was that power in many places, especially in less densely populated areas, is transmitted in above-ground power lines that are easily hit by falling trees. Many people interviewed by the media blamed the power companies both for indirectly causing the power outages by making insufficient investments, for example by not burying power lines, as well as for the long duration of the outages due to lack of personnel and equipment to handle the crisis. ${ }^{7}$ In the backwash of the storm, the government both increased the minimum levels of power-outage compensation paid to households and shortened the outage duration required before compensation has to be paid.

Besides studying the effect of experience on respondents’ WTP, we investigate the effect of 
reducing hypothetical bias by using cheap talk. Cheap talk has been one of the most successful attempts in terms of reducing hypothetical bias in closed-ended surveys (Cummings and Taylor, 1999). The original idea was to bring down the hypothetical bias in closed-ended contingent valuation surveys by thoroughly describing and discussing the propensity of respondents to exaggerate their WTP. Indeed, a number of papers have shown that cheap talk scripts can successfully reduce the hypothetical bias in closed-ended contingent valuation surveys (e.g., Cummings and Taylor, 1999; List, 2001; Brown et al., 2003; Bulte et al., 2005; Aadland and Caplan, 2006). However, the effect and the formulation of a cheap talk script for open-ended valuation questions are not necessarily the same as in the closed-ended case, not least because of the incentives to understate the true WTP. Given the discussion and views presented in the media, we stressed that individuals' responses are sometimes an expression of a particular view, in our case that everyone should have the right to power without outages. The script also pointed out that individuals sometimes state either a lower or a higher WTP than they are actually willing to pay. We hypothesize that a cheap talk script will decrease the share of respondents stating a zero WTP. The effect on the conditional WTP is less clear, since the script should make some respondents decrease and some increase their WTP.

The rest of the paper is organized as follows. Section 2 describes our contingent valuation survey, focusing especially on the three different treatments: the contingent valuation survey (i) before the storm and without the cheap talk script, (ii) after the storm and without the cheap talk script, and (iii) after the storm and with the cheap talk script. Section 3 presents and discusses the results. We analyze the effect of experience of the storm by 
comparing treatments (i) and (ii), and the effect of the cheap talk script by comparing treatments (ii) and (iii). Finally, Section 4 concludes the paper.

\section{The Survey}

The final questionnaire consisted of three parts. The first part contained questions about housing conditions, for example whether the homes could be heated without electricity. The second part consisted of the contingent valuation survey and the last part of socio-economic questions. The questionnaire was developed in collaboration with representatives from various power companies and from engineering researchers on power outages. ${ }^{8}$ The questionnaire was tested in several smaller focus groups and in a pilot study mailed to 200 individuals at the beginning of 2004.

In the contingent valuation survey, the respondents were asked to state their maximum WTP for avoiding a power outage of a certain duration starting at $6 \mathrm{pm}$ on a January evening, which is supposed to represent a worst case scenario. ${ }^{9}$ We included planned (announced at least 3 weekdays in advance) and unplanned outages, each type lasting for 1 , 4, 8, and 24 hours. For unplanned outages, we also included a case where the duration of the outage was uncertain in a 2-6 hour interval, with an equal probability of ending at any time during this time period. Thus, the respondents answered a total of nine valuation questions (4 planned, 5 unplanned). The respondents were explicitly told that for each question, they should state the maximum amount their households would be willing to pay in Swedish kronor ${ }^{10}$ (SEK) to avoid one power outage of the kind stated in the question. 
The original contingent valuation survey was conducted in May $2004 .{ }^{11}$ While we were analyzing the results, the storm Gudrun hit parts of Sweden in January 2005. Therefore, we decided to conduct a follow-up contingent valuation study with exactly the same design as the survey sent out before the storm. This means that we did not include any specific questions about the storm and to what extent the respondents had been affected by it. Although doing so would have revealed interesting information, we wanted to keep the surveys identical to make them completely comparable. In addition, we sent out a questionnaire that included a cheap talk script, but that in all other aspects was exactly the same as the original survey. The contingent valuation part of the questionnaire including the cheap talk treatment is presented below in Figure 1 (the version without the cheap talk script did not include the box with bold text).

>> FIGURE 1

Thus, our study contains three treatments: (i) before the storm without cheap talk, (ii) after the storm without cheap talk, and (iii) after the storm with cheap talk. In the analysis, we test for the effect of having experienced the storm by comparing treatments (i) and (ii), and we test for the effect of the cheap talk script by comparing treatments (ii) and (iii).

\section{Results}

Our samples were randomly drawn from a register containing all individuals aged 18-75 with a permanent address in Sweden. The first treatment was sent out to 3,000 individuals 
in May 2004. Each of the two other treatments was sent out to 500 individuals in April 2005. The response rates were $56 \%$ for the original treatment, $47 \%$ for the treatment after the storm without the cheap talk, and $49 \%$ for the cheap talk script treatment. Comparing the sample statistics of the three treatments with Swedish population statistics, we find no statistical difference at the $5 \%$ level in terms of gender composition and geographic representation (based on the postal codes). However, there is a slight and significant overrepresentation of older people in all three treatments. There is no significant difference among the three treatments with respect to gender composition, geographic representation, and age. The descriptive statistics of the main socio-economic characteristics of the three samples are presented in Table 1.

>> TABLE 1

There are no significant differences in socio-economic characteristics among the three samples. Note that there is no significant difference in the number of self-protecting measures taken between the samples before and after the storm. Hence, this cannot explain any potential difference in WTP.

Table 2 below presents the descriptive statistics of the WTP responses to each of the nine different valuation questions. We report the mean WTP for the overall sample, the proportion of respondents with zero WTP, and the mean WTP conditional on a positive WTP. The overall results are as expected: Overall mean WTP increases and the share of zero WTP decreases as the length of the power outage increases, and the overall WTP is 
higher and the proportion of zeros is lower for unplanned outages compared to for planned outages. Moreover, the overall WTP for the uncertain power outage with an expected duration of 4 hours is higher than the overall WTP for a power outage that will definitely last 4 hours. The conditional WTP, i.e., the WTP given it exceeds zero, follows the same pattern as the overall WTP.

>> TABLE 2

To compare the different treatments, we conduct both non-parametric and regression analyses. Our regression models aim to analyze the probability of a positive WTP, the conditional WTP (i.e., given that WTP is positive), and the overall WTP response by controlling for observed and unobserved individual characteristics in all three cases. A number of more or less restrictive regression models can be applied to this type of data, where one main decision relates to how to treat the zero WTP responses; see, e.g., Carlsson and Johansson-Stenman (2000) and Moeltner and Layton (2002). One feature of most socalled selection models is that they are modeled with a correlation between the first stage (in our case the probability of a positive WTP response) and the second stage (the conditional WTP). In the present paper, we analyze positive WTP, conditional, and overall WTP separately. ${ }^{12}$ We use a random-effect probit model for the positive WTP, and a linear regression model with random-effects for the WTP response conditional on a positive WTP. Finally, for the overall WTP responses we estimate a random-effects Tobit model. We define the following index function for the unobserved (latent) $W T P_{i t}^{*}$ 


$$
W T P_{i t}^{*}=x_{i t} \beta+u_{i}+\varepsilon_{i t} \text {, }
$$

where $i$ indicates the individuals and $t$ is an indicator for repeated contingent valuation responses for an individual; $x_{i t}$ are vectors of the exogenous variables and $\beta$ is the corresponding coefficient vector to be estimated; $u_{i}$ is the unobserved individual-effects, and they are assumed to be orthogonal to both error terms $\left(\varepsilon_{i t}\right)$ and to the observed individual characteristics following the standard random-effects assumption. In order to analyze the probability of a positive $W T P$, we define the observation criterion for the index function (1) as $r_{i t}=1\left(W T P^{*}>0\right)$ specifying a random-effects probit model, where $r_{i t}$ is a dummy variable that is 1 if WTP is positive and 0 otherwise. In this model, the error terms are assumed to be normally distributed with zero mean and unit variance due to identification. As a more rigorous way to deal with the zero WTP and analyze the overall WTP responses, we consider the zero WTP as a discrete corner outcome and follow the criterion $W T P=\max \left(W T P^{*}, 0\right)$ specifying a random-effects Tobit model censored below zero. The error terms of this model are assumed to be normally distributed with zero mean and variance.

As explanatory variables, we include eight dummy variables for each of the different contingent valuation questions except for the one-hour planned power outage, which is used as a reference case in the analysis. To test for the effect of having experienced Gudrun, we include a dummy variable. This approach assumes that experience results in a 
shift of the preferences. In addition to analyzing the pure treatment effects, we also estimate models in which socio-economic variables were included. In order to consider the effects of the cheap-talk script, we include dummy variables in a similar fashion as for experience.

\subsection{Before and after the storm}

Let us begin with a comparison between before and after the storm without a cheap talk script to investigate the effect of experience. Table 3 summarizes the before-after differences in overall WTP, in proportions of respondents with a positive WTP and in WTP conditional on positive WTP. In addition, we report the p-values of the tests of the null hypothesis of no difference between treatments, i.e., before and after the storm. For the overall WTP and the conditional WTP we use the Mann-Whitney test, and for the share of zero WTP we use a Chi-square test. These results are shown in the three middle columns of the table. For all outage durations, the overall mean WTP is higher for the sample that received the survey before the storm. This result seems to be explained by an increase in the proportion of respondents with zero WTP, which in all nine cases is lower for the treatment before the storm. As shown in Column 4, there is a significant difference in the overall WTP at the 5\% significance level in five out of the nine valuation questions. Interestingly, the null hypothesis of an equal proportion of zero WTP is rejected in the same five cases. Moreover, if we look at the conditional mean WTP, i.e., the mean WTP for respondents with a positive WTP, there is no statistically significant difference at any conventional level between before and after the storm in any of the nine questions (see Column 6). Thus, the higher overall WTP before the storm is due to a lower proportion of respondents with zero WTP. 
>> TABLE 3

The first regression model presented in Table 4 is based on the responses from the treatments before and after the storm without a cheap talk script. The first model analyzes whether or not a positive WTP has been reported. The marginal effects (estimated at the sample means) obtained with the random-effects probit model are shown. The effects are as expected and in line with the descriptive statistics presented in Table 1, i.e., the probability of a positive WTP increases with duration and is higher for unplanned than for planned outages. We reject the null hypothesis of no Gudrun effect on the probability of stating a positive WTP since the Gudrun variable (indicating that the valuation was conducted postGudrun) is significant. In the second model, we analyze the conditional WTP. We do not find a significant effect of experience on the conditional WTP. Most interesting from the regressions that include the socio-economic variables is that we find that people living in more populated areas are significantly more likely to have a positive WTP, but the effect on conditional WTP is insignificant. Both living in a detached or terraced house and living in a dwelling that cannot be heated during an outage have a significant and positive impact on the conditional WTP. Age and being female have a negative and significant impact on the probability of stating a positive WTP. Income has, as expected, a positive and significant effect both on the probability of stating a positive WTP and of stating a higher conditional WTP. In the Tobit model, the Gudrun variable is negative and significant and the socioeconomic characteristics have the same sign as in the probit model. 
>> TABLE 4

\subsection{With and without a cheap talk script}

Next we analyze the effect of the cheap talk script, which was included in half of the treatments sent out after the storm. We find (see Table 3) that the overall mean WTP is significantly different at the $5 \%$ level between the two treatments in three out of the nine valuation questions. Moreover, the share of respondents stating zero WTP is consistently lower with the cheap talk script, and the difference in shares is statistically significant at the $5 \%$ level in six cases out of nine (see Table 3, Column 8). Again, there is no statistically significant difference at the $5 \%$ level between the two treatments in any of the nine questions with respect to conditional WTP (see Table 3, Column 9). The results of the nonparametric analysis of the difference between with and without cheap talk in Table 3 are confirmed in the regression analysis in Table 4. The effect of the cheap talk script is parametrically analyzed in the same way as experience. In Model 4 (Table 4), where the

probability of stating a positive WTP is analyzed, there is a significantly higher probability of stating a positive WTP, while there is no significant difference in the conditional WTP between the two treatments. People living in more populated areas are significantly more likely to have a positive WTP, while age has a negative and significant impact on the probability of stating a positive WTP. Income has, as expected, a positive and significant effect on conditional WTP. In the Tobit model, the cheap talk variable is positive and significant and the socio-economic characteristics have the same sign as in the probit model. 


\section{Conclusions}

By using an open-ended contingent valuation survey, we have analyzed the effects of (i) having experienced the storm Gudrun and of (ii) using a cheap talk script on people’s stated maximum WTP to avoid power outages. Having experience resulted in a significant increase in the proportion of respondents stating a zero WTP, while conditional WTP was not significantly affected. This cannot be explained by an increase in self-protective measures after the storm. One reasonable explanation is that the experience of an outage actually affected the preferences of some respondents. This relates to the literature on the difference between decision and experience utility (Kahneman and Snell, 1992). Although outages do occur from time to time, they are not frequently experienced in Sweden. This means that respondents could have difficulties in predicting the negative experiences of an outage. Another possible explanation for the difference in WTP before and after the storm is that the respondents, in line with the view presented in the media, disagree with the implied property rights, i.e., that consumers do not have the right to power without outages. In light of this, it might seem tempting to apply a compensation question and instead ask for minimum willingness to accept (WTA), which would then change the property right to the consumers. However, research on WTA has shown a large discrepancy between these two measures. For example, Horowitz and McConnell (2002) found a mean WTA/WTP ratio of around seven in a meta-study using 200 previously conducted contingent valuation studies. Thus, applications of WTP can be seen as a conservative valuation approach. Our results point to the fact that it is difficult to use a particular question format, since different respondents have different views on property rights. This is a general problem when applying valuation to cases where property rights are ambiguous. The cheap talk script, 
which was mainly intended to avoid underestimation of WTPs, seems to have counteracted the effect of expressing an attitude since it increased the proportion of non-zero responses.

The cheap-talk script resulted in a decrease in the number of respondents stating a zero WTP. The share of zero WTP responses tends to be large in open-ended CV studies, and this is the case in our study as well. One explanation for this is strategic behavior, which then results in a lower WTP. If this is the case, then our cheap-talk script seems to reduce the hypothetical bias and increase WTP. The literature presents mixed effects of using cheap talk scripts, but there is evidence that a neutral script such as the one used here can increase WTP and increase hypothetical bias (Aadland and Caplan, 2006). However, it is important to distinguish between different elicitation formats. Most studies use a closeended format, where a positive hypothetical bias is expected. In our study, an open-ended format is used, where it is less clear what the direction of hypothetical bias is.

From a policy perspective, our results are interesting and important since they show that valuation may differ before and after a negative event. This can be compared with the results in Ajzen et al. (1996), who found a strong information effect on WTP for a good that is relevant for the respondent compared to an irrelevant good. The changes in valuation are likely to be driven by the expression of new attitudes and more experience, but the $a$ priori net effect on WTP is unknown. A related issue is the long-term effect; e.g., Kunreuther (1996) found that people hit by flooding or other natural disasters are more likely to purchase insurance, but as time passes they cancel their policies and regress to their previous behavior. Whether this is the case also for power outages is an empirical 
question. Thus, for valuation studies taking place shortly after for example a natural disaster, it is important to test the sensitivity in the elicited valuation by conducting studies at more than one point in time and by using a cheap talk script. Moreover, as shown in Aadland and Caplan (2006), the length of the cheap talk seems to be important, but of course the wording of the script is also important. Thus, there is clearly a need for more research on applications of cheap talk as an instrument to improve the quality of preferences elicited from stated preference surveys. This paper has shed some light on the critical question of whether people's stated preferences are affected by a negative event and on the effect of different strategies to investigate this issue. 


\section{References}

Aadland, D. and A.J. Caplan. 2006. “Cheap talk reconsidered: New evidence from CVM. “ Journal of Economic Behavior and Organization 60: 562-78.

Ajzen, I., T.C. Brown and L.H. Rosenthal, H. Lori. 1996. "Information bias in contingent valuation: effects of personal relevance, quality of information, and motivational orientation.” Journal of Environmental Economics and Management 30: 43-57.

Balisteri, E, G. McClelland, G. Poe and W. Schulze. 2001.“Can Hypothetical Questions Reveal True Answers? A Laboratory Comparison of Dichotomous Choice and Openended Contingent Values with Auction Values." Environmental and Resource Economics 18: 275-92.

Brown, T., P. Champ, R. Bishop and D. McCollum. 1996. "Which Response Format Reveals the Truth about Donations to a Public Good?.” Land Economics 72: 152-66.

Brown, T.C., I. Ajzen and D. Hrubes. 2003. "Further tests of entreaties to avoid hypothetical bias in referendum contingent valuation.” Journal of Environmental Economics and Management 46: 353-61.

Bulte, E., S. Gerking, J.A. List, J.A. and A. de Zeeuw. 2005. "The Effect of Varying the Causes of Environmental Problems on Stated Values: Evidence from a Field Study.” Journal of Environmental Economics and Management 49: 330-42.

Cameron, T.A. and J. Englin. 1997. "Respondent experience and contingent valuation of environmental goods.” Journal of Environmental Economics and Management 33: 296-313.

Carlsson, F. and O. Johansson-Stenman. 2000. "Willingness to Pay for Improved Air Quality in Sweden.” Applied Economics 32: 661-70.

Carlsson, F. and P. Martinsson. 2007. "Willingness to Pay Among Swedish Households to Avoid Power Outages - A Random Parameter Tobit Model Approach.” Energy Journal 28: 75-89.

Carson, R., T. Groves and M. Machina. 2000. "Incentive and Information Properties of Preference Questions.” Department of Economics, Working Paper, University of California.

Cummings, R.G. and L.O. Taylor. 1999. "Unbiased Value Estimates for Environmental Goods: A Cheap Talk Design for the Contingent Valuation Method.” American Economic Review 89: 649-65.

Horowitz, J.K. and K.E. McConnell. 2002. “A review of WTA/WTP studies.” Journal of Environmental Economics and Management 44: 426-47.

Kahneman, D., I. Ritov and D.A. Schkade. 1999. "Economic Preferences or Attitude Expressions?: An Analysis of Dollar Responses to Public Issues.” Journal of Risk and Uncertainty 19: 203-35.

Kahneman, D. and J. Snell. 1992. "Predicting a changing taste: Do people know what they will like?” Journal of Behavioral Decision Making 5, 187-200.

Kahneman, D., P. Wakker and R. Sarin 1997. "Back to Bentham: explorations of experienced utility.” Quarterly Journal of Economics 112, 375-405.

Kriström, B. 1993. “Comparing Continuous and Discrete Contingent Valuation Questions.” Environmental and Resource Economics 3: 63-71.

Kunreuther, H. 1996. "Mitigating Disaster Losses through Insurance.” Journal of Risk and Uncertainty 12: 171-187. 
List, J. 2001. "Do Explicit Warnings Eliminate the Hypothetical Bias in Elicitation Procedures? Evidence from Field Auctions for Sports Cards.” American Economic Review 91: 1498-1507.

List, J. and C. Gallet. 2001. "What Experimental Protocol Influence Disparities between Actual and Hypothetical Stated Values?.” Environmental and Resource Economics 20: 241-54.

Lowenstein, G. 1996. "Out of control: visceral influences on behavior." Organizational Behavior and Human Decision Processes 65: 272-292.

Moeltner, K. and D. Layton. 2002. “A Censored Random Coefficients Model for Pooled Survey Data with Application to the Estimation of Power Outage Costs." Review of Economics and Statistics 84: 552-61.

Svenska Elverksföreningen. 1994. "Avbrottskostnader för Elkunder." Svenska Elverksföreningen, Stockholm (in Swedish).

Statens Energimyndighet. 2005. ”Energimarknaden 2005.” Elander Berlings, Malmö.

Svenska Kraftnät. 2002. ”Ett Robust Elförsörjningssystem.” Svenska Kraftnät, Stockholm (in Swedish).

Whitehead, J.C., G.C. Blomquist, T.J. Hoban and W.B. Clifford. 1995. “Assessing the validity and reliability of contingent values: A comparison of on-site users, off-site users, and non-users.” Journal of Environmental Economics and Management 29: 238-51. 
Figure 1. Scenario and WTP question, with cheap talk script.

We will now ask some questions regarding your household's willingness to avoid power outages. Imagine that there is a service with a backup electricity board that can be used in case of a power outage. This electricity board will cover your household's need for electricity during the whole outage. You will only pay the power company if an outage actually occurs. If you do not want to pay anything, your household will experience power outages since you will then not be connected to the backup electricity board. There are two types of outages, and we would like your answers for both of them:

- Planned outage: An outage that you have been notified in advance about.

- Unplanned outage: An outage that comes as a surprise and that you have not been notified in advance about.

Imagine that an outage occurs on an evening in January and that the outage starts at $6 \mathrm{pm}$. For each question we ask you to answer how much your household at most would be willing to pay in order to avoid this outage by using the backup service. We ask you to consider your answers as carefully as possible and to remember that it is also possible to answer zero kronor.

Experiences from similar studies show that people have a tendency to answer one thing but in reality may want to do something else. For example, you may state a lower amount of money than what you would actually be willing to pay, e.g. that you answer zero kronor. We believe that this sometimes can be due to one wanting to express a view that one for example has the right to have uninterrupted distribution of power. Others may answer a higher amount than what they actually would be willing to pay. We do not want you to think in this way when answering our questions. There might also be other reasons why you answer the way you do. If you have any thoughts about this, please write down your thoughts at the end of the survey.

\section{Planned outages}

How much would your household at most be willing to pay in order to avoid a power outage that starts at 6 pm on an evening in January? You know in advance that the outage will occur. We ask you to answer all $\underline{4}$ questions below.

\begin{tabular}{l|l|r}
\hline & \multicolumn{1}{|c|}{ Duration of the outage } & \multicolumn{1}{c}{$\begin{array}{c}\text { I am at most willing to pay } \\
\text { (round to whole numbers) }\end{array}$} \\
\hline Question 1 & 1 hour & kronor \\
\hline Question 2 & 4 hour & kronor \\
\hline Question 3 & 8 hour & kronor \\
\hline Question 4 & 24 hour & kronor \\
\hline
\end{tabular}

\section{Unplanned outages}

How much would your household at most be willing to pay in order to avoid a power outage that starts at 6 pm on an evening in January? You do not know in advance that the outage will occur. We ask you to answer all $\underline{5 \text { questions below. }}$

\begin{tabular}{l|l|r}
\hline & \multicolumn{1}{|c|}{ Duration of outage } & \multicolumn{1}{c}{$\begin{array}{c}\text { I am at most willing to pay } \\
\text { (round to whole numbers) }\end{array}$} \\
\hline Question 5 & 1 hour & kronor \\
\hline Question 6 & 4 hours & kronor \\
\hline Question 7 & 8 hours & kronor \\
\hline Question 8 & 24 hours & kronor \\
\hline Question 9 & $\begin{array}{l}\text { Between 2 and 6 hours. It is equally likely that the power } \\
\text { returns after 2 hours as after 6 hours, or at any time in between. }\end{array}$ & kronor \\
\hline
\end{tabular}


Table 1. Descriptive statistics of the socio-economic variables.

\begin{tabular}{|c|c|c|c|c|c|c|c|}
\hline \multirow[t]{2}{*}{ Variable } & \multirow[t]{2}{*}{ Description } & \multicolumn{2}{|c|}{$\begin{array}{l}\text { Before Gudrun } \\
\text { No cheap talk }\end{array}$} & \multicolumn{2}{|c|}{$\begin{array}{l}\text { After Gudrun } \\
\text { No cheap talk }\end{array}$} & \multicolumn{2}{|c|}{$\begin{array}{l}\text { After Gudrun } \\
\text { Cheap talk }\end{array}$} \\
\hline & & Mean & Std. & Mean & Std. & Mean & Std. \\
\hline City & $=1$ if more than 10,000 inhabitants; 0 otherwise & 0.644 & 0.479 & 0.612 & 0.488 & 0.637 & 0.482 \\
\hline House & $=1$ if detached or terraced house; 0 otherwise & 0.631 & 0.482 & 0.618 & 0.487 & 0.632 & 0.483 \\
\hline Cannot heat & $\begin{array}{l}=1 \text { if dwelling cannot be heated during outage; } 0 \\
\text { otherwise }\end{array}$ & 0.391 & 0.489 & 0.397 & 0.490 & 0.415 & 0.494 \\
\hline Age & Age in years & 48.15 & 15.04 & 47.95 & 14.56 & 46.63 & 14.04 \\
\hline Female & $=1$ if female respondent & 0.484 & 0.500 & 0.485 & 0.501 & 0.505 & 0.501 \\
\hline Income & Monthly household income after tax, in 10,000 SEK. & 2.485 & 1.208 & 2.523 & 1.167 & 2.542 & 1.178 \\
\hline Self-protection & Number of self-protective measures taken & 2.302 & 1.086 & 2.245 & 1.082 & 2.434 & 1.114 \\
\hline Number of obser & & 1518 & & 204 & & 212 & \\
\hline
\end{tabular}


Table 2. Descriptive statistics of the overall stated WTP in SEK, proportion of zero WTP, and conditional WTP in SEK (standard deviations in parentheses).

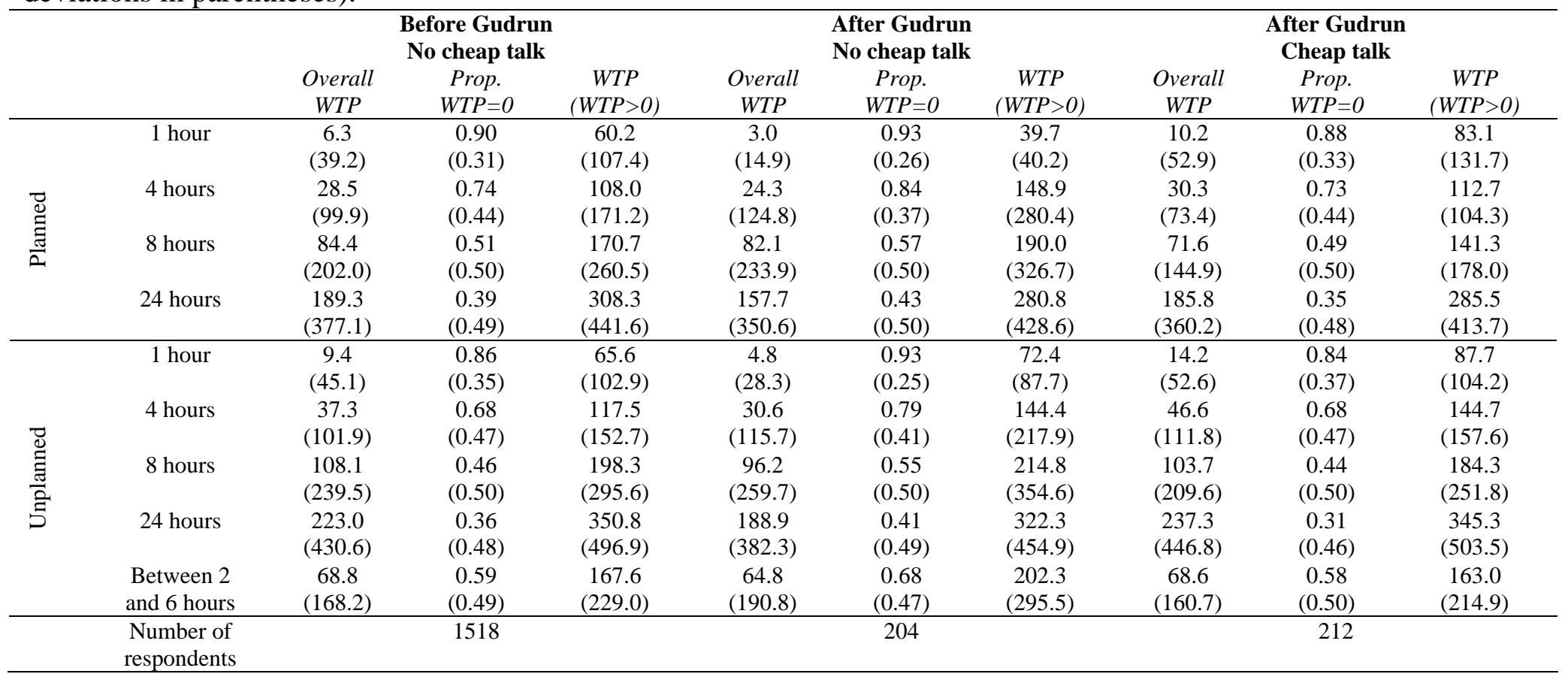


Table 3. Difference in mean WTP in SEK and p-values from non-parametric tests of the null hypothesis of no difference between the treatments.

\begin{tabular}{|c|c|c|c|c|c|c|c|c|}
\hline & & & \multicolumn{3}{|c|}{$\begin{array}{c}\text { Change in experience: } \\
\text { Before - After }\end{array}$} & \multicolumn{3}{|c|}{$\begin{array}{c}\text { Introduction of cheap talk: With - } \\
\text { Without }\end{array}$} \\
\hline & & & $\begin{array}{l}\text { Overall } \\
\text { WTP }\end{array}$ & $\begin{array}{c}\text { Prop. } \\
W T P=0\end{array}$ & $\begin{array}{c}W T P \\
(W T P>0)\end{array}$ & $\begin{array}{c}\text { Overall } \\
\text { WTP }\end{array}$ & $\begin{array}{c}\text { Prop. } \\
W T P=0\end{array}$ & $\begin{array}{c}\text { WTP } \\
(W T P>0)\end{array}$ \\
\hline \multirow[t]{8}{*}{ Planned } & 1 hour & Difference & 3.3 & -0.03 & 20.5 & 7.2 & -0.05 & 43.4 \\
\hline & & p-value & 0.19 & 0.14 & 0.92 & 0.94 & 0.10 & 0.42 \\
\hline & 4 hours & Difference & $4.2 * *$ & $-0.10 * *$ & -40.9 & $6.0^{*}$ & $-0.11 *$ & -36.2 \\
\hline & & p-value & 0.00 & 0.00 & 0.87 & 0.01 & 0.01 & 0.30 \\
\hline & 8 hours & Difference & 2.3 & -0.06 & -19.3 & -10.5 & -0.08 & -48.7 \\
\hline & & p-value & 0.18 & 0.09 & 0.50 & 0.31 & 0.12 & 0.22 \\
\hline & 24 hours & Difference & 31.6 & -0.04 & 27.5 & 28.1 & -0.08 & 4.7 \\
\hline & & p-value & 0.16 & 0.19 & 0.64 & 0.16 & 0.07 & 0.75 \\
\hline \multirow[t]{10}{*}{ Unplanned } & 1 hour & Difference & $4.6^{* *}$ & $-0.07 * *$ & -6.8 & $9.4 * *$ & $-0.09 * *$ & 15.3 \\
\hline & & p-value & 0.00 & 0.00 & 0.79 & 0.00 & 0.00 & 0.57 \\
\hline & 4 hours & Difference & $6.7^{* *}$ & $-0.11^{* *}$ & -26.9 & $16.0^{*}$ & $-0.11^{*}$ & 0.3 \\
\hline & & p-value & 0.00 & 0.00 & 0.81 & 0.01 & 0.01 & 0.39 \\
\hline & 8 hours & Difference & $11.9 *$ & $-0.09 *$ & -16.5 & 7.5 & $-0.11^{* *}$ & -30.5 \\
\hline & & p-value & 0.02 & 0.01 & 0.90 & 0.05 & 0.00 & 0.61 \\
\hline & 24 hours & Difference & 34.1 & -0.05 & 28.5 & 48.4 & $-0.10^{*}$ & 23 \\
\hline & & p-value & 0.19 & 0.18 & 0.80 & 0.11 & 0.03 & 0.69 \\
\hline & Between 2 & Difference & $4.0^{*}$ & $-0.09 *$ & -34.7 & 3.8 & $-0.10 *$ & -39.3 \\
\hline & and 6 hours & p-value & 0.04 & 0.02 & 0.44 & 0.06 & 0.04 & 0.83 \\
\hline
\end{tabular}

Note: $* *$ denotes significant at the $1 \%$ level and $*$ at the $5 \%$ level. We applied the Mann-Whitney test for overall WTP and conditional WTP to test the null hypothesis that the two treatments come from the same distribution, while a chi-squared test is applied for the proportions. 
Table 4. Marginal effects for estimated models on experience and cheap talk (standard errors in parentheses).

\begin{tabular}{|c|c|c|c|c|c|c|}
\hline & \multicolumn{3}{|c|}{ Experience } & \multicolumn{3}{|c|}{ Cheap talk } \\
\hline & Model (1) & Model (2) & Model (3) & Model (4) & Model (5) & Model (6) \\
\hline & $\begin{array}{l}\text { Random-Effects } \\
\text { Probit }\end{array}$ & $\begin{array}{c}\text { Random-Effects } \\
\text { Linear }\end{array}$ & $\begin{array}{c}\text { Random-Effects } \\
\text { Tobit }\end{array}$ & $\begin{array}{l}\text { Random-Effects } \\
\text { Probit }\end{array}$ & Random-Effects & Random-Effects \\
\hline & $\mathrm{P}(\mathrm{WTP}>0)$ & $\begin{array}{l}\text { Conditional } \\
\text { WTP }\end{array}$ & $\begin{array}{l}\text { Overall } \\
\text { WTP }\end{array}$ & $\mathrm{P}(\mathrm{WTP}>0)$ & $\begin{array}{l}\text { Conditional } \\
\text { WTP }\end{array}$ & $\begin{array}{l}\text { Overall } \\
\text { WTP }\end{array}$ \\
\hline \multirow{2}{*}{ Planned 4 hours } & $0.544 * * *$ & $23.94 * *$ & $56.93 * * *$ & $0.443^{* * *}$ & 58.76 & $47.20 * * *$ \\
\hline & $(0.034)$ & (10.85) & (4.939) & $(0.077)$ & (21.59) & (8.513) \\
\hline \multirow{2}{*}{ Planned 8 hours } & $0.882 * * *$ & $87.07 * * *$ & $146.0 * * *$ & $0.889 * * *$ & $128.94 * * *$ & $130.0 * * *$ \\
\hline & $(0.010)$ & $(10.30)$ & $(6.543)$ & $(0.020)$ & $(20.33)$ & $(11.56)$ \\
\hline \multirow{2}{*}{ Planned 24 hours } & $0.919 * * *$ & $207.9 * * *$ & $244.22 * * *$ & $0.936 * * *$ & $230.3^{* * *}$ & $214.6^{* * *}$ \\
\hline & $(0.010)$ & $(10.21)$ & (7.867) & $(0.016)$ & $(20.10)$ & $(14.01)$ \\
\hline \multirow{2}{*}{ Unplanned 1 hour } & $0.133^{* * *}$ & -1.510 & $13.64 * * *$ & 0.051 & 0.476 & 7.054 \\
\hline & $(0.034)$ & $(11.92)$ & (4.109) & $(0.055)$ & $(23.66)$ & (6.989) \\
\hline \multirow{2}{*}{ Unplanned 4 hours } & $0.681 * * *$ & $44.37 * * *$ & $79.60 * * *$ & $0.595 * * *$ & $93.83^{* * *}$ & $69.58 * * *$ \\
\hline & $(0.027)$ & $(10.70)$ & $(5.398)$ & $(0.069)$ & (21.30) & $(9.481)$ \\
\hline \multirow{2}{*}{ Unplanned 8 hours } & $0.900 * * *$ & $115.4^{* * *}$ & $172.6 * * *$ & $0.908 * * *$ & $160.4^{* * *}$ & $153.43^{* * *}$ \\
\hline & $(0.010)$ & $(10.28)$ & (6.964) & $(0.018)$ & $(20.34)$ & $(12.40)$ \\
\hline \multirow{2}{*}{ Unplanned 24 hours } & $0.923^{* * *}$ & $230.5^{* * *}$ & $265.5^{* * *}$ & $0.941 * * *$ & $260.9 * * *$ & $245.43^{* * *}$ \\
\hline & $(0.010)$ & $(10.23)$ & (8.109) & $(0.015)$ & (20.19) & $(14.80)$ \\
\hline \multirow{2}{*}{ Unplanned between 2 and 6 hours } & $0.825^{* * *}$ & $88.91^{* * *}$ & $126.77 * * *$ & $0.796 * * *$ & $122.0 * * *$ & $106.75 * * *$ \\
\hline & $(0.014)$ & $(10.62)$ & $(6.406)$ & $(0.038)$ & $(21.05)$ & $(11.08)$ \\
\hline \multirow{2}{*}{ City } & $0.146^{* * *}$ & 21.63 & $23.39 * * *$ & $0.251 * * *$ & -17.70 & $30.48 * * *$ \\
\hline & $(0.034)$ & (13.69) & $(5.602)$ & $(0.061)$ & $(24.17)$ & $(10.14)$ \\
\hline \multirow[t]{2}{*}{ House } & 0.004 & $68.13^{* * *}$ & $11.702 * *$ & 0.108 & 32.25 & $20.03 *$ \\
\hline & $(0.042)$ & $(14.26)$ & $(6.083)$ & $(0.067)$ & $(25.92)$ & $(11.36)$ \\
\hline \multirow[t]{2}{*}{ Cannot heat } & $0.063 *$ & $33.89 * *$ & $15.17 * * *$ & 0.008 & 15.85 & 7.400 \\
\hline & $(0.036)$ & (13.23) & $(5.558)$ & $(0.065)$ & $(23.36)$ & $(10.48)$ \\
\hline \multirow[t]{2}{*}{ Age } & $-0.006^{* * *}$ & -0.191 & $-0.727 * * *$ & $-0.007 * *$ & $-1.382 * *$ & $-1.105^{* * *}$ \\
\hline & $(0.001)$ & $(0.393)$ & $(0.173)$ & $(0.002)$ & $(0.721)$ & $(0.354)$ \\
\hline \multirow[t]{2}{*}{ Female } & $-0.092 * * *$ & -6.236 & $-13.07 * *$ & -0.045 & -10.41 & -7.580 \\
\hline & $(0.034)$ & $(11.76)$ & $(5.102)$ & $(0.060)$ & $(20.81)$ & $(9.655)$ \\
\hline \multirow{2}{*}{ Income } & $0.044 * * *$ & $24.98 * * *$ & $11.564 * * *$ & -0.004 & $27.77^{* * *}$ & $7.217^{*}$ \\
\hline & $(0.015)$ & $(4.956)$ & $(2.228)$ & $(0.027)$ & $(9.093)$ & $(4.348)$ \\
\hline Gudrun (post Gudrun valuation) & $\begin{array}{l}-0.118^{* * *} \\
(0.032)\end{array}$ & $\begin{array}{l}-23.80 \\
(18.61)\end{array}$ & $\begin{array}{l}-16.64^{* *} \\
(6.864)\end{array}$ & - & - & - \\
\hline Cheap talk script & - & - & - & $\begin{array}{l}0.148 * * \\
(0.063)\end{array}$ & $\begin{array}{l}3.790 \\
(20.749)\end{array}$ & $\begin{array}{l}16.67 * \\
(9.641)\end{array}$ \\
\hline Variance of unobserved effects & $2.622 * * *$ & 184.9 & $307.4^{* * *}$ & $2.560 * * *$ & 157.0 & $287.1^{* * *}$ \\
\hline
\end{tabular}




\begin{tabular}{llllll}
$(0.0612)$ & & $(7.761)$ & $(0.126)$ & & $(14.78)$ \\
$0.873^{* * *}$ & 0.726 & $0.776^{* * *}$ & $0.868^{* * *}$ & 0.689 & $0.819^{* * *}$ \\
$(0.005)$ & & $(0.009)$ & $(0.011)$ & & $(0.016)$ \\
0.00 & 0.00 & 0.00 & 0.00 & 0.00 & 0.00 \\
1721 & 1143 & 1721 & 415 & 272 & 415 \\
14824 & 5648 & 14689 & 3537 & 1281 & 3502 \\
\hline
\end{tabular}

Number of respondents

Number of observations

5648

14689

Note: Marginal effects of the parameters are obtained by evaluating the first derivative of the conditional expectations at the mean values of the explanatory variables (The marginal effect of constant is not reported). We used different number of Gaussian-Quadrature points in the estimation of the tobit model to test the sensitivity and the results stabilized after $60-70 . *, * *$, and $* * *$ indicate $1 \%, 5 \%$, and $10 \%$ significance levels respectively. In the estimations we deleted outliers, which we defined as WTP above 1000 SEK, and they corresponded to $0.8 \%$ of total number of observed WTP answers. 
${ }^{1}$ This is related to the literature on experience of for example visiting national parks; see for example Cameron and Englin (1997) and Whitehead et al. (1995). However, in our case individuals are not self-selected as in the case of a visit to a national park.

${ }^{2}$ The storm is called Gudrun in the Nordic countries, while it is internationally known as Erwin. This storm made its way from Ireland to Russia during 7-9 January 2005.

${ }^{3}$ On average, a Swedish household experiences one outage per year. An average outing lasts around 20 minutes for households located in populated areas and 200 minutes for households in sparsely populated areas (Svenska Kraftnät, 2002).

${ }^{4}$ It would of course have been interesting to include questions directly related to the storm, but the trade-off would have been to give up the idea of having exactly the same survey as before. Since we decided to use exactly the same survey, we can rule out that respondents were affected differently by different questionnaire formats.

${ }^{5}$ Using a WTP question implies that the customers do not have the right to power. Thus, the choice of elicitation format relates to property rights.

${ }^{6}$ The clearing of forest was dangerous work. About ten people were killed and several injured. Another related issue discussed was the risk of an invasion of vermin, especially bark beetles, unless the timber was removed from the forest fairly soon after the storm.

${ }^{7}$ In 1996, the Swedish electricity market was reformed from being a completely regulated domestic market to a completely liberalized Nordic (including Norway, Denmark, and Finland) market. To create an incentive to make investments to reduce both the number and length of power outages, a performance assessment model has been developed for evaluation of the quality of the supply of electricity. One part of the electricity bill paid by the households relates to the tariff for transmission of electricity, and the network companies determine the level of the tariff since there is no market for transmission of electricity. However, the tariffs charged by the network companies have to be "reasonable" according to Swedish Law, utilizing the network performance assessment model for this purpose. For example, the network companies have to submit reports to the Swedish National Energy Administration, and the report has to include the amount of transmitted electricity, the tariffs charged for transmission, where their customers are located etc. In addition, the report has to include quality aspects such as the number of outages and the duration of the outages. Based on this information, it is possible, by using the network performance assessment model, to calculate the value to the households of the services provided by the network companies. The value is reduced if for example outages have occurred. In order to calculate whether the tariffs charged to the households are reasonable or not, the actual tariffs charged are divided by the calculated value of the services from the network performance assessment model. If the obtained ratio exceeds unity, then the network company has charged more than the value of the services provided to its customers and vice versa. In cases when the network companies have overcharged their customers, they have to pay back the same amount to them. It should also be noted that since the reform of the electricity market in Sweden, there has been closure of reserve capacity as a means to reduce costs (Svenska Kraftnät, 2002).

${ }^{8}$ The complete questionnaire is available upon request.

${ }^{9}$ Our scenario is similar to the previously conducted 1994 study in Sweden on power outages (Svenska Elverksföreningen, 1994).

${ }^{10}$ At the time of the survey in mid-May 2004, the exchange rate was 1 USD=7.70 SEK, while in mid-April 20051 USD=7.10 SEK.

${ }^{11}$ For details on that survey and its results, see Carlsson and Martinsson (2007).

${ }^{12}$ We also tried to estimate a random-effects sample selection model (following the suggestions of the referees). However, any credible analysis of selection requires a robust identifying instrument (identification or exclusion restrictions) and in our case, the number of variables usable for this purpose is very limited. In most of the cases it was impossible to make the likelihood functions converged or obtain stabile parameter estimates. 